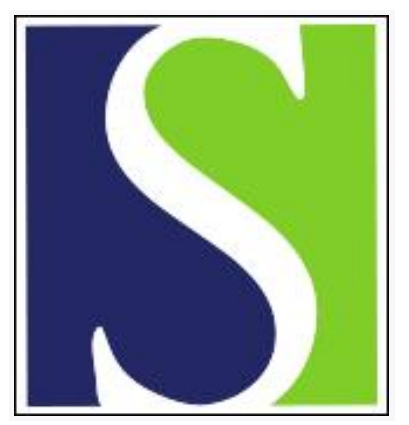

Scand J Work Environ Health 2006;32(4):300-309

https://doi.org/10.5271/sjweh.1014

Issue date: 31 Aug 2006

Changes in neuromuscular function due to intermittently increased workload during repetitive work in cold conditions

by Oksa J, Sormunen E, Koivukangas U, Rissanen S, Rintamäki H

Affiliation: Finnish Institute of Occupational Health; Aapistie 1; FI-90220 Oulu; Finland. email: juha.oksa@ttl.fi

Key terms: cold conditions; cold exposure; electromyographic gap; electromyography; neuromuscular function; neuromuscular performance; repetitive work; workload

This article in PubMed: www.ncbi.nlm.nih.gov/pubmed/16932828

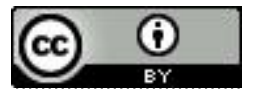




\title{
Changes in neuromuscular function due to intermittently increased workload during repetitive work in cold conditions
}

\author{
by Juha Oksa, PhD, ${ }^{1}$ Erja Sormunen, MSc, ${ }^{2}$ Ulla Koivukangas, MSc, ${ }^{3}$ Sirkka Rissanen, PhD, ${ }^{1}$ Hannu \\ Rintamäki, $P h D^{1,4}$
}

\begin{abstract}
Oksa J, Sormunen E, Koivukangas U, Rissanen S, Rintamäki $\mathrm{H}$. Changes in neuromuscular function due to intermittently increased workload during repetitive work in cold conditions. Scand J Work Environ Health 2006;32(4):300-309.
\end{abstract}

Objectives This study attempted to determine whether repetitive work in the cold affects the number of
electromyographic (EMG) gaps and whether cold-induced deterioration in neuromuscular function can be
restored by altering work intensity.
Methods During 2 hours of simulated sausage packing, the occurrence of EMG gaps was studied in eight
upper-extremity muscles at $19^{\circ} \mathrm{C}$ and $4^{\circ} \mathrm{C}$. The additional effect of continuous, light repetitive work [wrist
flexion-extension $10 \%$ of the maximal voluntary contraction (MVC), $\mathrm{C}_{\text {work }}$ ] and intermittently increased
workload ( $10 \%$ or $30 \%$ MVC) ( $\left.\mathrm{I}_{\text {work }}\right)$ on forearm muscle EMG gaps, the median frequency of the EMG
spectrum, EMG activity, and muscle fatigue (as indicated by changes in the MVC of wrist flexion) at $4^{\circ} \mathrm{C}$ was
studied.

Results During work simulation, the mean skin temperature decreased from 33.3 (SD 0.1$)^{\circ} \mathrm{C}$ to 30.6 (SD $0.2)^{\circ} \mathrm{C}(\mathrm{P}<0.05)$, and the number of EMG gaps diminished in seven muscles by $1.4-68.2 \%(\mathrm{P}<0.05)$. During $\mathrm{I}_{\text {work }}$ there were $44 \%$ and $37 \%$ more EMG gaps in the forearm flexors and extensors, respectively, and the median frequency shifted to higher frequencies $(\mathrm{P}<0.05)$ as compared with the situation in $\mathrm{C}_{\text {work }}$. The average EMG activity of the forearm flexors was $13 \%$ lower $(\mathrm{P}<0.05)$ during $\mathrm{I}_{\text {work }}$ than during $\mathrm{C}_{\text {work }}$. Wrist flexion MVC decreased $18 \%$ and $15 \%$ in $\mathrm{C}_{\text {work }}$ and $\mathrm{I}_{\text {work }}$, respectively.

Conclusions The cold-induced decrease in the number of EMG gaps and increased muscle strain and fatigue can be, at least partially, restored by intermittently increasing the workload (ie, breaking the monotonous work cycle).

Key terms cold exposure; electromyographic gap; electromyography; neuromuscular performance.

Overuse injuries and musculoskeletal symptoms and disorders are a common problem, especially in industries in which repetitive work and cold are combined, such as in the food processing industry (1). It has been reported that cold complaints and, for example, upperlimb disorders are more frequent in the food processing industry than in similar thermally neutral workplaces (2-4). Overuse injuries and musculoskeletal symptoms and disorders result in a decrease in work capacity, human suffering, and substantial financial losses. It has been estimated that, in the member countries of the $\mathrm{Eu}$ ropean Union, the annual costs of musculoskeletal dis- orders vary between $0.5 \%$ and $2.0 \%$ of the gross national product (5).

One factor that has been considered to be a precursor of overuse injuries and musculoskeletal symptoms and disorders is fatigue of the working muscles (6). When work is being done in the cold, this type of fatigue needs to be taken into account since it has been shown that, in subnormal muscle temperatures, more muscle fibers must be recruited to produce a given work output successfully (7). For example, when low-intensity repetitive work is being done in the cold at $10 \%$ of the maximal voluntary contraction $(10 \% \mathrm{MVC})$,

1 Finnish Institute of Occupational Health, Oulu, Laboratory of Physiology, Finland.

2 Center of Arctic Medicine, University of Oulu, Finland.

3 Department of Biology, University of Oulu, Finland.

4 Department of Physiology, University of Oulu, Finland.

Reprint requests to: Dr J Oksa, Finnish Institute of Occupational Health; Aapistie 1; FI-90220 Oulu; Finland. [E-mail: email: juha.oksa@ttl.fi] 
electromyographic (EMG) activity and fatigue of the working forearm muscles has been found to be almost twofold when compared with the same work in thermoneutral conditions (8). One possible reason for the high muscle load and fatigue may be that, in low intensity stereotypic activation of the muscle, the same lowthreshold motor units are the first to be recruited and that these units are active throughout the contraction (9, 10). This phenomenon is the so-called "Cinderella theory" (11). The use of the same fibers throughout work may accelerate the onset of fatigue, and this acceleration may, in the long run, lead to overuse symptoms and injuries and eventually to musculoskeletal disorders (10). Other possibilities may be, for example, that skin cooling can increase the number of motor units recruited (12), the motor unit recruitment pattern may be altered (7), or increased antagonist activity due to the cold has to be balanced with increased agonist activity $(13,14)$.

In normally functioning muscle, physiological gaps (EMG gaps) (ie, short silent periods or resting periods of the muscle) can be found during work. The occurrence of EMG gaps can be considered to indicate that normal variation in fiber recruitment takes place (15). The occurrence of EMG gaps also seems to have importance in terms of well-being at work. In the longitudinal study of Veiersted et al (16) concerning female employees at a chocolate manufacturing plant, future trapezius myalgia patients had a lower frequency of EMG gaps than nonpatients, and a regression analysis indicated that a low rate of gaps predicts future patient status.

It is not known how cooling affects the occurrence of EMG gaps. It is known that, with subnormal muscle temperature, the fast twitch fibers are the first to be dropped (7) and thus the slower fibers are left at work. In addition, subnormal muscle temperature has numerous adverse effects on neuromuscular function (eg, decreased maximal force and slower muscle contraction velocity, as well as decreased nerve conduction velocity). [For a review, see the Oksa (17).] Since, in lowintensity repetitive work, the slow fibers are already at work and cold diminishes the use of faster fibers, our first hypothesis was that the occurrence of EMG gaps in a cold environment is reduced when compared with the situation in the same work in a thermoneutral environment. Our second hypothesis is that increasing the workload intermittently increases the number of EMG gaps and induces higher EMG spectral frequency, lower EMG activity, and less fatigue (indicated by smaller changes in MVC) than during light, continuous repetitive work.

Work simulation and intermittent work studies were conducted. The first was performed to evaluate whether the number of EMG gaps decreases during work in a cold environment. The second was performed to evaluate whether the number of EMG gaps and the EMG spectral frequency could be increased and the EMG activity and fatigue of the working muscles could be decreased by intermittently increasing the workload of low-intensity repetitive work.

\section{Study population and methods}

\section{Study population}

Sixteen ( 8 men and 8 women, work simulation study) and eight healthy (5 men and 3 women, intermittent work study) nonsmoking persons volunteered for the study. Their physical characteristics are presented in table 1 . All of them were informed of all the details of the experimental procedures and the associated risks and discomforts. After a medical examination, each worker gave his or her written informed consent. They were asked to abstain from exhausting exercise and from consuming caffeine and alcohol for 12 hours before the experimental sessions. All of the procedures were conducted according to the guidelines of the Declaration of Helsinki, and the experimental protocol was approved by the Ethics Committee of the Hospital District of Helsinki and Uusimaa.

\section{Work simulation study}

Thermal exposures and temperature measurements. The ambient temperature and clothing were chosen according

Table 1. Physical characteristics of the participants according to participation in the work simulation and intermittent work studies.

\begin{tabular}{|c|c|c|c|c|c|c|c|c|}
\hline \multirow[t]{2}{*}{ Type of study } & \multicolumn{2}{|c|}{ Age (years) } & \multicolumn{2}{|c|}{ Body height (cm) } & \multicolumn{2}{|c|}{ Body mass (kg) } & \multicolumn{2}{|c|}{ Subcutaneous fat (\%) } \\
\hline & Mean & SD & Mean & SD & Mean & SD & Mean & SD \\
\hline \multicolumn{9}{|l|}{ Work simulation } \\
\hline Men $(\mathrm{N}=8)$ & 25 & 4 & 180 & 5 & 75 & 12 & 14 & 5 \\
\hline Women $(\mathrm{N}=8)$ & 23 & 3 & 160 & 5 & 57 & 4 & 24 & 3 \\
\hline \multicolumn{9}{|l|}{ Intermittent work } \\
\hline Men (N=5) & 22 & 1 & 179 & 4 & 74 & 8 & 13 & 2 \\
\hline Women $(\mathrm{N}=3)$ & 24 & 1 & 168 & 4 & 59 & 6 & 23 & 2 \\
\hline
\end{tabular}


to actual circumstances that can be found in the food processing industry in Finland. Each person was exposed to ambient temperatures of $19^{\circ} \mathrm{C}$ (thermoneutral, $\mathrm{TN})$ and $4^{\circ} \mathrm{C}$ (cold, C) for 120 minutes in a random order. The intervening time between the exposures was 2 days. In both conditions, the participants were dressed in a long-sleeved undershirt and long-legged underpants, thermal underwear, and special outerwear designed for the food processing industry. They wore their own shoes, but no gloves. The estimated thermal insulation of the clothing was 1.6 clo (18).

Rectal temperature $\left(\mathrm{T}_{\mathrm{re}}, 10-\mathrm{cm}\right.$ depth) and skin temperatures from 15 different sites (cheek, chest, lower back, neck-shoulder (trapezius muscle, right and left), shoulder, extensor and flexor side of the upper and lower arm, palm, finger, thigh, calf, and foot) were continuously measured from the right side of the body with thermistor probes (YSI 400 Series, Yellow Springs Instruments, Inc, Yellow Springs, CO, USA) at 1-minute intervals into a data logger (Squirrel 1200, Grant, UK). The temperature probes were fixed to the skin with surgical tape. The mean skin temperature $\left(T_{\text {sk }}\right)$ was calculated by weighing the local skin temperatures by representative areas according to Hardy \& Dubois (19). Local forearm skin flexor $\left(\mathrm{T}_{\text {flexor }}\right)$ and extensor $\left(\mathrm{T}_{\text {extensor }}\right)$ temperatures were also analyzed.

Work simulation. The work simulation mimicked actual work in a sausage packing department at a Finnish meat packing factory as closely as possible. This work on an assembly line includes rapid, bilateral arm movements using small-muscle groups mainly in the forearm. In the work simulation, the products handled were artificial sausages (about 12 centimeters long, 3.5 centimeters in diameter and 125 grams in weight) corresponding to the real products in the meat-packing factory. The artificial sausages were in packs of four, bound together with string at the other end. During the work simulation the participants picked up the four-pack product group (500 g) from the right side of the body with the right hand. Then the product group was divided between both hands (two sausages in both hands), while the string kept the products together. The string in between the sausages was touched against a blade, thus simulating the cutting phase in the factory. After the cutting phase, the fourpack product group was moved back to the right hand and placed into a box located in front of the body (figure 1A). A single work phase lasted for 3-4 seconds. The work was paced by a metronome so that the participants worked at a rate of 15 phases per minute. The work simulation was continuous, lasted for 30 minutes, and was repeated four times (altogether 120-minute exposure).

EMG gaps. EMG activity was measured throughout each 30-minute work period from the right side of the body from the extensor digitorum (ED), flexor carpi radialis (FCR), triceps brachii (TB), and biceps brachii (BB) muscles, the anterior and medial part of the deltoideus (DE) muscle, and the superior part of the trapezius muscle (TRA, both left and right side) (mE3000P8, Mega Electronics, Kuopio, Finland). Pre-gelled bipolar surface electrodes (Medicotest, M-OO-S, electrodes, Olstykke,
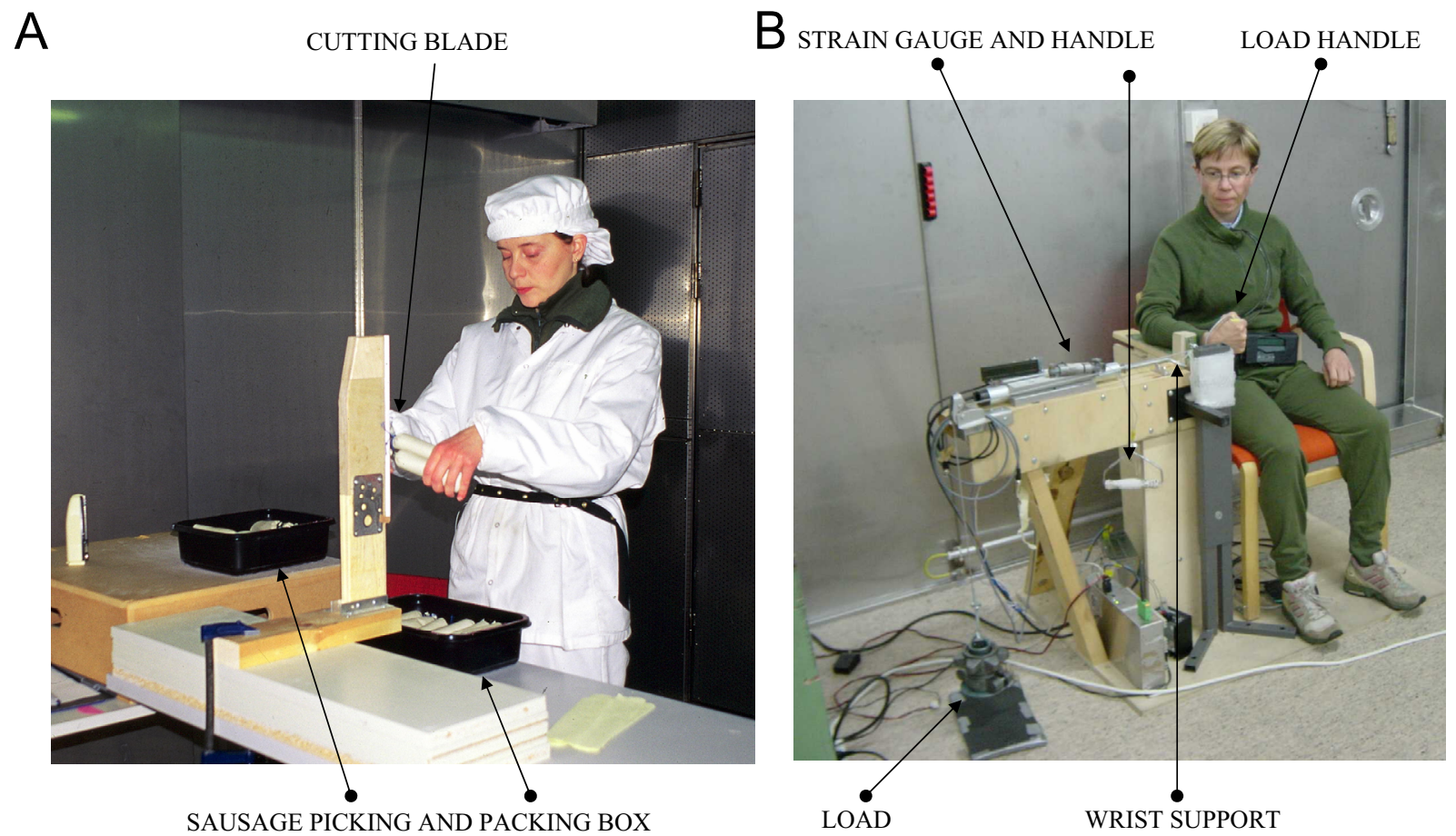

Figure 1. Experimental setup in the work simulation study (A) and the intermittent work study (B). 
Denmark) were placed over the belly of the muscle, and the distance between the recording contacts was 2 centimeters. Ground electrodes were attached above inactive tissue. Skin hair was shaved, and skin was cleaned with alcohol to ensure the proper attachment of the electrodes. In addition, their initial locations were carefully marked on the skin with permanent waterproof drawing ink to assure the constant location of the electrodes on the skin over the conditions. The markings were clearly visible throughout the experiments.

The EMG signals from the skin above the working muscles were acquired with a sample rate of $1000 \mathrm{~Hz}$. The measured signal was amplified 2000 times (preamplifier situated 10 centimeters from the measuring electrodes), and the signal band, $20-500 \mathrm{~Hz}$, was full-wave rectified and averaged with a 0.1 -second time constant. The EMG gaps were analyzed according to the following criterion: EMG activity less than $20 \mu \mathrm{V}$ for at least 300 milliseconds.

\section{Intermittent work study}

Thermal exposures and temperature measurements. Each person was exposed twice to $4^{\circ} \mathrm{C}$, the intervening time between the exposures being at least 2 days. During both exposures the participants performed six 20minute work bouts (total duration 120 minutes) and were dressed in a T-shirt, shorts, tracksuit, socks, and jogging shoes. The estimated thermal insulation of the clothing was 0.9 clo (18).

$\operatorname{Rectal}\left(\mathrm{T}_{\mathrm{re}}, 10-\mathrm{cm}\right.$ depth) and skin temperatures from 10 different sites (forehead, chest, lower back, upper arm, flexor and extensor side of the lower arm, hand, front thigh, calf, and foot) (NTC thermistors, Digi-Key, River Falls, MI, USA, and datalogger, Hewlett Packard, HP 3497, Palo Alto, CA, USA) were measured similarly as in the work simulation study.

External work. Each participant was seated with the hip and elbow angle adjusted at 90 degrees. The armrest of the seat supported the relaxed forearm (alongside the torso). The participant held a handle in his or her hand (with the handle and the palm of the hand in a vertical position), and a metal wire running through a pulley system was attached to the handle. A load corresponding to either $10 \%$ MVC (maximal voluntary contraction force of the wrist flexors, see force measurement) or $30 \%$ MVC was fixed to the other end of the wire. Starting with their wrist fully extended, each participant flexed the wrist every third second to the full free range of joint motion and returned the hand to the starting position (figure 1B). These dynamic concentric-eccentric contractions were paced with a metronome so that there were 20 contractions per minute (each contraction lasting for about 1 second every 3 seconds).
During the first exposure to $4^{\circ} \mathrm{C}$, the participants performed continuous wrist flexion-extension repetitive work at $10 \% \operatorname{MVC}\left(\mathrm{C}_{\text {work }}\right)$. This workload was chosen because it is recommended that, during dynamic work lasting 1 hour or more, the load corresponding to $10 \%$ MVC should not be exceeded (20). In the second exposure to $4^{\circ} \mathrm{C}$, the same work was performed with the exception that every fourth minute the workload was intermittently $\left(\mathrm{I}_{\text {work }}\right)$ increased to $30 \%$ MVC and the participants performed a double contraction (two consecutive wrist flexions) in 1 second. The loads corresponding to $10 \%$ or $30 \%$ MVC were $2-4 \mathrm{~kg}$ and $6-12 \mathrm{~kg}$, respectively.

EMG measurements. At the beginning of the first work bout and at the end of each work bout, the EMG activity from the four forearm muscles, wrist flexors (flexor carpi radialis and flexor digitorum superficialis muscles) and wrist extensors (brachioradialis and extensor carpi radialis muscles) were measured for 30 seconds as in the work simulation study, with the exception that the averaging time constant was 0.01 seconds.

In addition, to assess the frequency component of the EMG, the power spectrum was estimated by moving fast Fourier transform (window, 512 points). From the power spectra, the median frequency was calculated to describe changes in the spectral frequency component. The EMG data were analyzed separately for concentric (wrist flexion) and eccentric (wrist extension) muscle contraction for amplitude (aEMG) and frequency (median frequency), these two phases being clearly distinct from each other (8). Since the results from the two flexor and extensor muscles were similar, their results are presented as means in the Results section.

Maximal wrist flexion force. At the beginning of the first work bout and at the end of each work bout, the MVC of the wrist flexors was measured in the same posture as in which external work was performed. Another handle was attached to a strain gauge (Newtest Inc, Oulu, Finland); it was capable of measuring the force produced by the maximal flexion of the wrist. The strain gauge was fixed to a level placed at a right angle to the armrest (figure 1B) and connected to a computer for further analysis. The forearm was fixed to the armrest of the chair so that only the motion of the wrist joint was allowed. The maximal force level was analyzed from the MVC data, and a decrease in the MVC value was considered a sign of muscle fatigue.

Statistics. The paired-samples T-test was used in both studies, and significance was accepted at the $\mathrm{P}<0.05 \mathrm{lev}-$ el. The results are expressed as the mean standard error of the mean (SE). 


\section{Results}

\section{Work simulation study}

Thermal responses. Rectal temperature remained stable during both exposures, the total 120 -minute average being $37.2(\mathrm{SE} 0.8)^{\circ} \mathrm{C}$ and $37.3(\mathrm{SE} 0.6)^{\circ} \mathrm{C}$ for the thermoneutral and cold conditions, respectively. However,
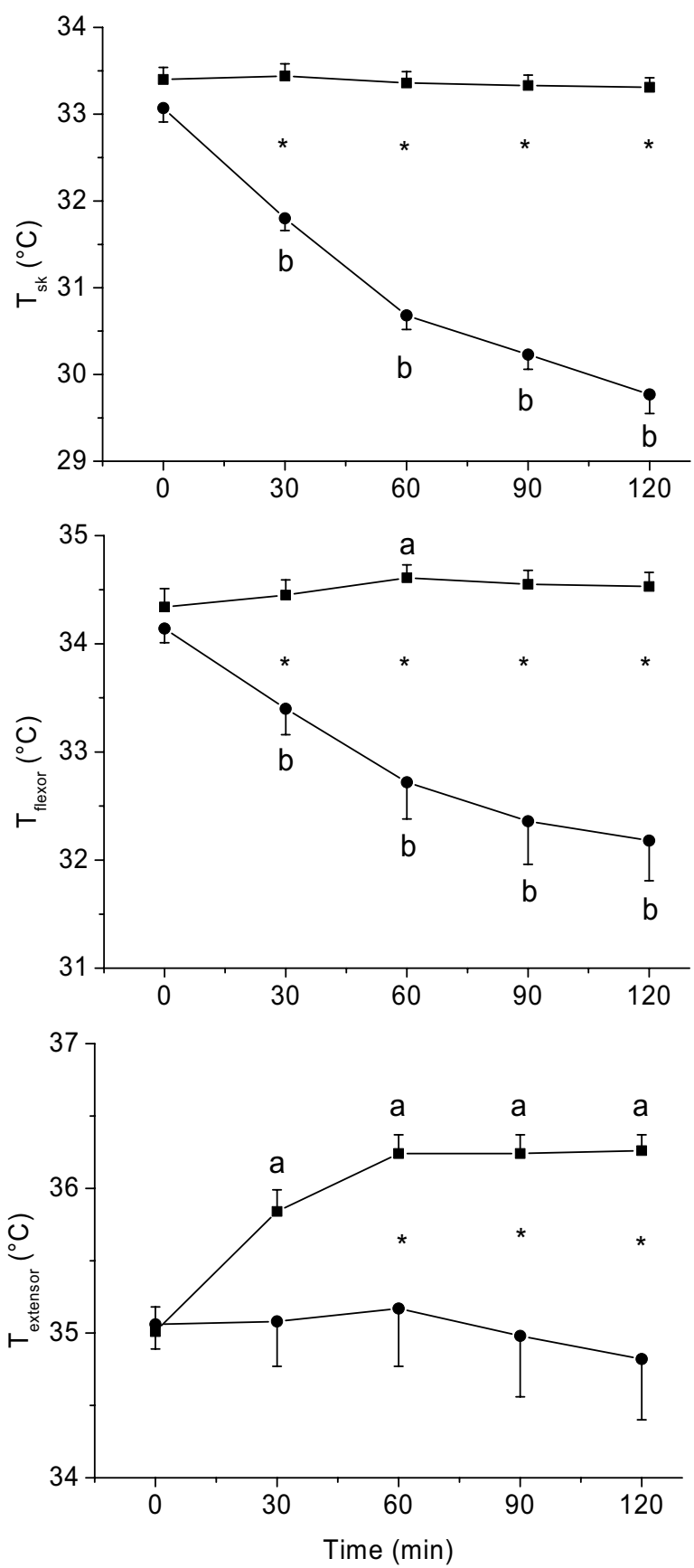

Figure 2. Thermal responses during simulated sausage packing in thermoneutral (squares) and cold (circles) conditions. $\left({ }^{*}=\right.$ significant difference $(P<0.05)$ between conditions, $a=$ significant difference in the thermoneutral condition as compared with the situation in the beginning of work, $b=$ significant difference in the cold conditions as compared with the situation in the beginning of work) the mean skin temperature and local wrist flexor and extensor temperatures were significantly lower in the cold than in thermoneutral conditions, as shown in figure 2 $(\mathrm{P}<0.05)$. Other local skin temperatures behaved in a manner similar to the wrist flexor and were also significantly lower in the cold $\left(0.8-3.0^{\circ} \mathrm{C}\right)$ than in thermoneutral conditions.

EMG gaps. Working in the cold decreased the number of EMG gaps in seven out of eight muscles (figure 3). The most pronounced decrement was found in the flexor carpi radialis muscle; there were $68.2 \%$ fewer gaps in the cold than in thermoneutral conditions. The smallest difference was found for the extensor digitorum muscle and a slight increase in the biceps brachii muscle (figure 3).

Figure 4 shows the time course for the EMG gap behavior of the four muscles that showed the largest difference between the thermoneutral and cold conditions.

\section{Intermittent work study}

Thermal responses and external work. The rectal temperature was slightly higher during $\mathrm{C}_{\text {work }}$ than during $\mathrm{I}_{\text {work }}$, but the difference was not significant. During both exercise modes the rectal temperature decreased an average of $0.7-1{ }^{\circ} \mathrm{C}$ (figure 5A). The average decrease in the mean skin temperature was $3.7^{\circ} \mathrm{C}$ and $4.0^{\circ} \mathrm{C}$ during $\mathrm{C}_{\text {work }}$ and $\mathrm{I}_{\text {work }}$, respectively $(\mathrm{P}<0.05$, figure $5 \mathrm{~B})$. Similarly, the change in the forearm flexor skin temperature $\left(\mathrm{T}_{\text {flexor }}\right)$ was practically the same between the two exercise modes. At the end of the work, the $\mathrm{T}_{\text {flexor }}$ averaged $0.7^{\circ} \mathrm{C}$ and $0.5^{\circ} \mathrm{C}$ higher in $\mathrm{C}_{\text {work }}$ and $\mathrm{I}_{\text {work }}$, respectively,

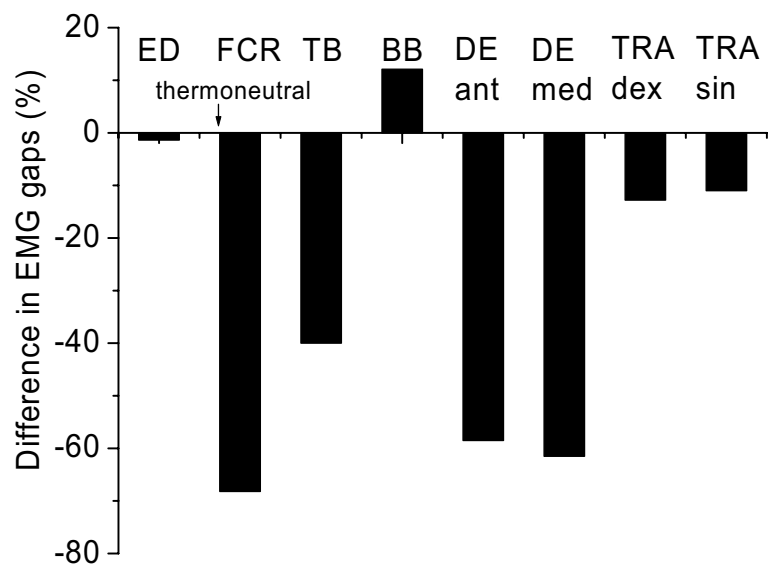

Figure 3. Percentage difference in the electromyographic (EMG) gaps in different muscles between the thermoneutral and cold conditions. The line at 0 represents the thermoneutral condition and a negative value indicates that there were fewer gaps in the cold. (ED = extensor digitorum muscle, $\mathrm{FCR}=$ flexor carpi radialis muscle, $\mathrm{TB}=$ triceps brachii muscle, $\mathrm{BB}=$ biceps brachii muscle, $\mathrm{DE}$ ant $=$ anterior part of the deltoideus muscle, DE med = medial part of the deltoideus muscle, TRA de $=$ trapezius muscle on the left side, TRA $\sin =$ trapezius muscle on the right side) 

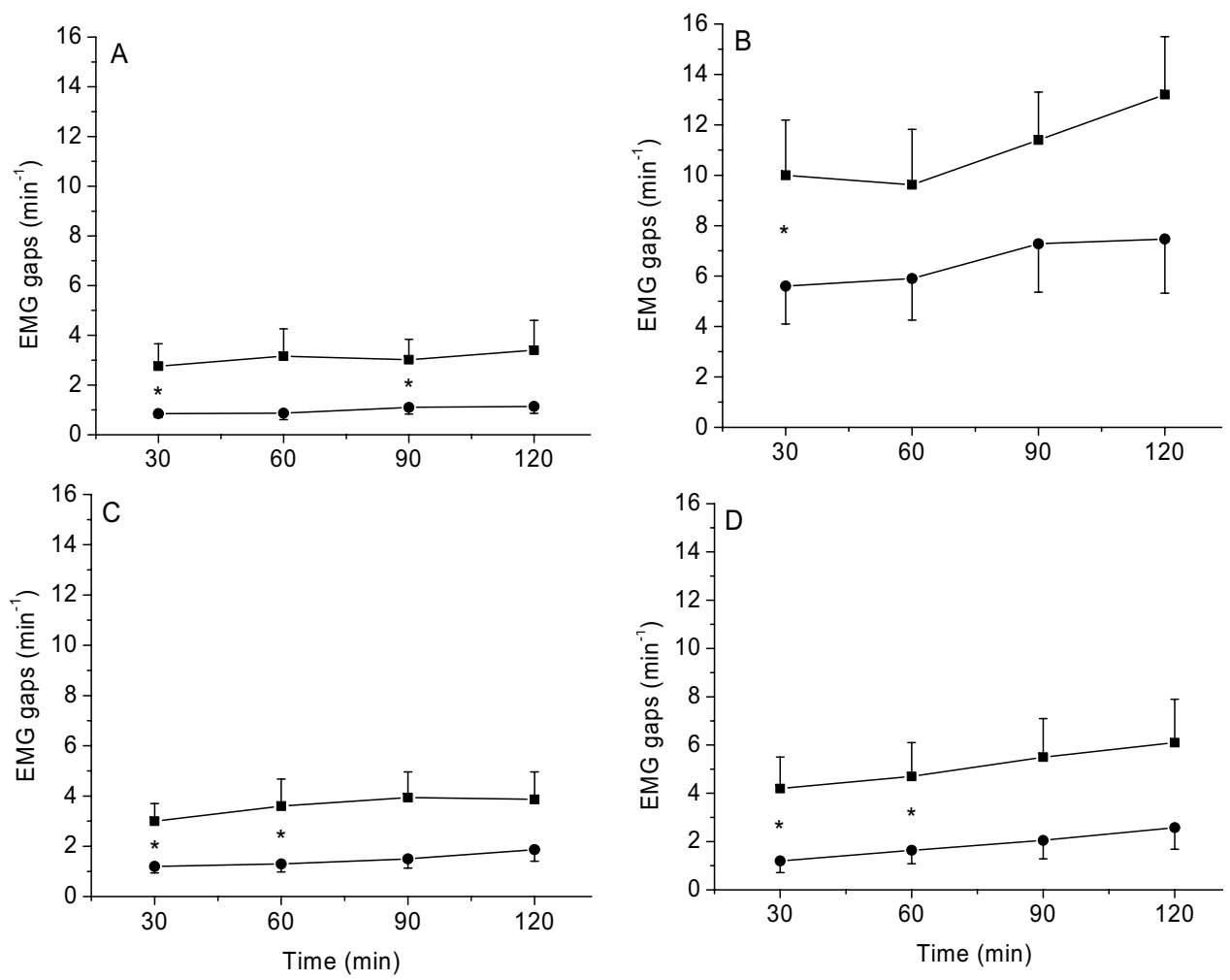

Figure 4. Frequency of electromyographic (EMG) gaps in the flexor carpi radialis muscle $(A)$, the triceps brachii muscle (B), the anterior part of the deltoideus muscle $(C)$ and the medial part of the deltoideus muscle (D) in thermoneutral (squares) and cold (circles) conditions. $\left({ }^{*}=\right.$ significant difference $(P<0.05)$ between conditions)
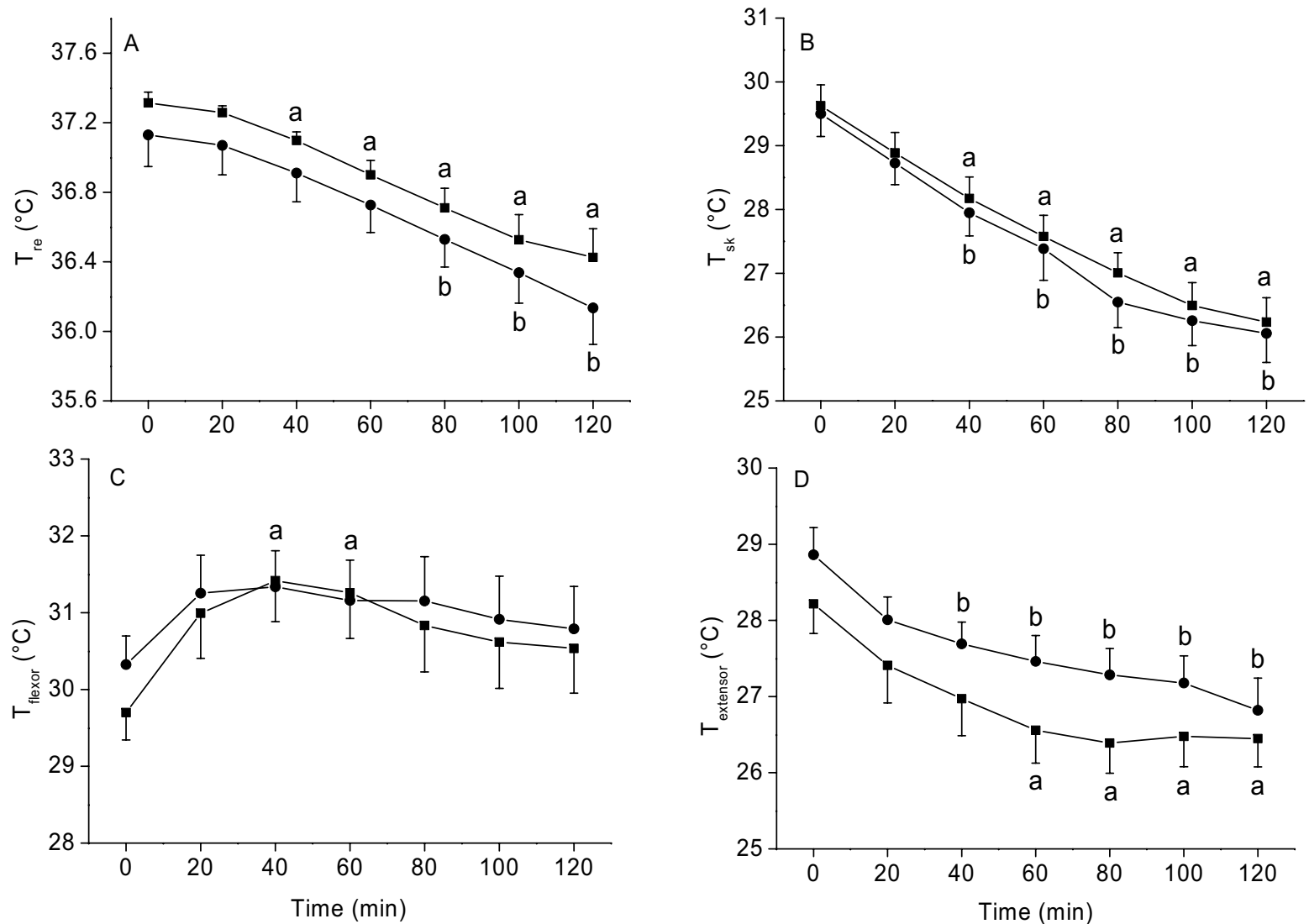

Figure 5. Thermal responses during the work simulation study in the cold $\left(C_{\text {work }}\right)$ (squares) and intermittent work study $\left(I_{\text {work }}\right)($ circles). $(\mathrm{a}=$ significant difference $(P<0.05)$ from the beginning of the work for $C_{\text {work }}, b=$ significant difference $(P<0.05)$ from the beginning of the work for $\left.I_{\text {work }}\right)$ 
than at the beginning of the work (figure 5C). The forearm extensor skin temperature $\left(\mathrm{T}_{\text {extensor }}\right)$ was higher (not significant) during $\mathrm{I}_{\text {work }}$ than during $\mathrm{C}_{\text {work }}$ (figure 5D).

The total accumulated lifted weight was 8939 (SE $320) \mathrm{kg}$ and 9476 (SE 339) $\mathrm{kg}(\mathrm{P}<0.05)$ during $\mathrm{C}_{\text {work }}$ and $\mathrm{I}_{\text {work }}$, respectively, the difference being $6 \%$.

EMG gaps and median frequency. During the flexionextension work, the number of EMG gaps in the forearm flexors and extensors was $44 \%$ and $37 \%$ higher $(\mathrm{P}<0.05)$ in $\mathrm{I}_{\text {work }}$ than in $\mathrm{C}_{\text {work }}$ (figures $6 \mathrm{~A}$ and $\left.6 \mathrm{~B}\right)$.

In $\mathrm{I}_{\text {work }}$ during the concentric phase of muscle contraction the median frequency for the forearm flexors was significantly higher than for $\mathrm{C}_{\text {work }}$ (figure 7A). During $I_{\text {work }}$, the median frequency was higher from 40 to 100 minutes as compared with the initial value. A similar tendency was also observed for the extensor muscles (figure 7B). During the eccentric phase, there was no difference between the median frequency of the exercise modes.

Average electromyography. In $\mathrm{I}_{\text {work }}$ during the concentric phase of muscle contraction, the EMG activity of the forearm flexors had a tendency to be lower after 40 minutes of work (figure 8A). There was no difference for the forearm extensors (figure 8B). During eccentric contraction, the situation was reversed. There were no differences between the forearm flexors, but, between
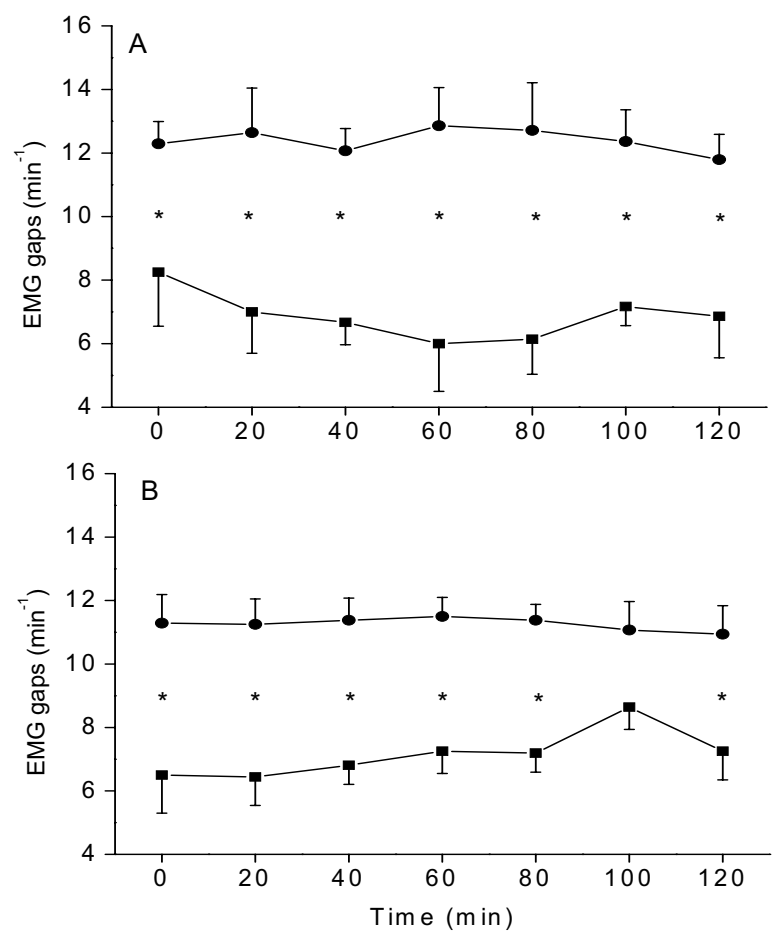

Figure 6. Frequency of electromyographic (EMG) gaps during the work simulation study in the cold $\left(\mathrm{C}_{\text {work }}\right)$ (squares) and the intermittent work study $\left(\mathrm{I}_{\text {work }}\right)$ (circles) in the wrist flexors $(\mathrm{A})$ and extensors $(\mathrm{B})$. ( ${ }^{*}$ $=$ significant difference $(P<0.05)$ between exposures $)$ the extensors during $I_{\text {work }}$, the EMG was significantly lower from 20 to 80 minutes of work (figures $8 \mathrm{C}$ and $8 \mathrm{D})$.

Maximal voluntary contraction. In the beginning of $\mathrm{C}_{\text {work }}$ and $\mathrm{I}_{\text {work }}$, the MVC of the wrist flexion was 319 (SE 11) and 320 (SE 12) N, respectively. The force level gradually decreased during both exercise modes, and it reached its lowest level at 120 minutes, being 262 (SE $12)$ and $272(\mathrm{SE} 13) \mathrm{N}(\mathrm{P}<0.05$ in relation to the beginning of exercise) for $\mathrm{C}_{\text {work }}$ and $\mathrm{I}_{\text {work }}$, respectively. The average percentage difference, compared with the beginning of the work, was $18 \%$ and $15 \%$ for $\mathrm{C}_{\text {work }}$ and $\mathrm{I}_{\text {work }}$, respectively. The MVC differed significantly from the first value after 60 minutes in $\mathrm{C}_{\text {work }}$ and after $80 \mathrm{~min}$ utes in $\mathrm{I}_{\text {work }}$.

\section{Discussion}

The results showed a decreased number of EMG gaps during low-intensity repetitive work in cold conditions; this finding reflects more continuous activation of the working muscles underneath the measuring electrodes. However, increasing the workload intermittently
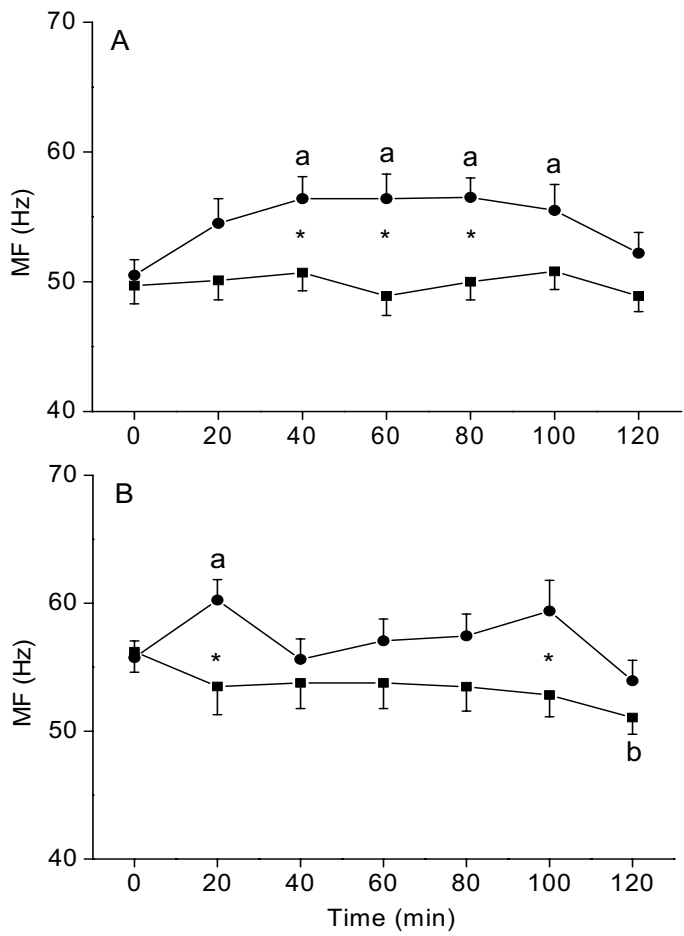

Figure 7. Median frequency of the wrist flexors (A) and extensors (B) during the concentric phase of muscle contraction in the work simulation study in the cold $\left(\mathrm{C}_{\text {work }}\right)$ (squares) and the intermittent work study $\left(I_{\text {work }}\right)$ (circles). $(a=$ significant difference $(P<0.05)$ from the beginning of the work for $C_{\text {work }}, b=$ significant difference $(P<0.05)$ from the beginning of the work for $I_{\text {work }}{ }^{*}=$ significant difference $(P<0.05)$ between the exposures) 

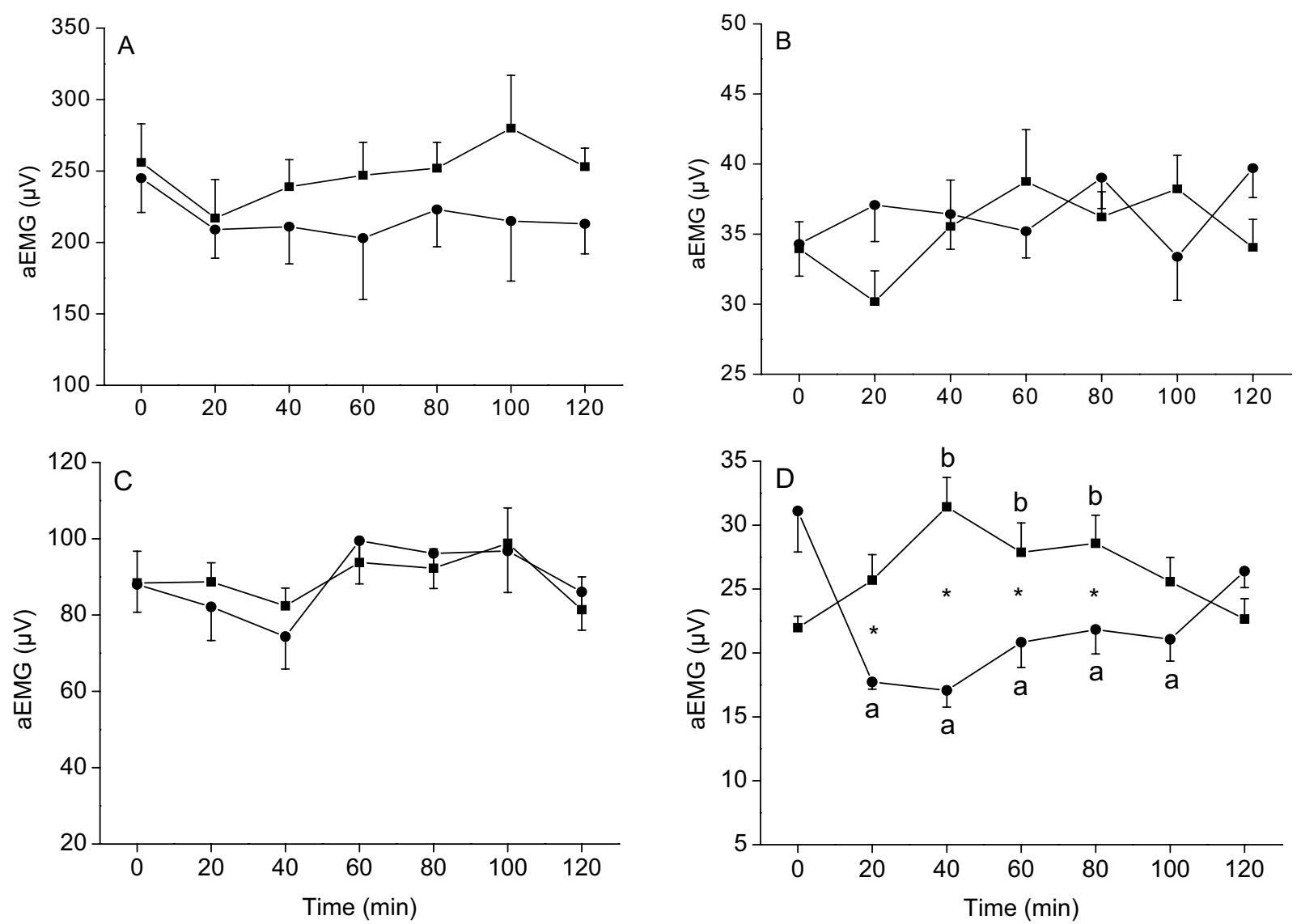

Figure 8. Average electromyography (aEMG) of the wrist flexors and extensors during the concentric $(A$ and $B)$ and eccentric $(C$ and $D)$ phase of muscle contraction. $\left(a=\right.$ significant difference $(P<0.05)$ from the beginning of the work in the work simulation study in the cold $\left(C_{\text {work }}\right), b=$ significant difference $(P<0.05)$ from the beginning of the work for the intermittent work study $\left(I_{\text {work }}\right),{ }^{*}=$ significant difference $(P<0.05)$ between the exposures $)$

induced changes that can be regarded as beneficial in terms of neuromuscular functioning. An increased number of EMG gaps, together with a higher muscle contraction frequency during $\mathrm{I}_{\text {work }}$, may indicate a more evenly distributed workload (and perhaps a more variable fiber recruitment), less fatigue and strain being induced regardless of the higher absolute workload.

In the work simulation study, in seven out of eight muscles, there was a clear reduction in the number of EMG gaps during the performance of low-intensity repetitive work in the cold. This finding may be an indication that the fibers underneath the measuring electrodes remained active throughout the work period. If true, then these fibers are at higher risk of localized fatigue, which may, in the long run, induce musculoskeletal symptoms and disorders. This assumption is supported by the finding of Veiersted et al (16), who found that future trapezius myalgia patients in a chocolate manufacturing plant had a lower frequency of EMG gaps than nonpatients.

There are studies indicating a more frequent occurrence of musculoskeletal complaints and disorders in cold work than in similar work in a thermally neutral environment $(21,22)$. If we assume that a reduction in EMG gaps takes place in cold work in general, and considering the results of Veiersted et al (16), we could postulate that one reason for the increased occurrence of musculoskeletal complaints and disorders in the cold is the lack of variation in fiber recruitment (smaller number of EMG gaps). If so, this phenomenon would need to be taken into account, since the decrement that occurs in $\mathrm{T}_{\text {sk }}$ in the cold is only $2.7^{\circ} \mathrm{C}$ lower than the corresponding thermoneutral condition, which takes place easily in an actual work situation.

In the intermittent work study, both exercise modes induced practically similar changes in thermal responses. The slightly higher flexor skin temperature observed during $I_{\text {work }}$ may be due to a higher starting temperature at the beginning of the work. Since the thermal responses during $\mathrm{C}_{\text {work }}$ and $\mathrm{I}_{\text {work }}$ were similar, the observed changes in the EMG parameters cannot be explained by thermal effects. Especially in median frequency, which has been found to be largely dependent on tissue temperature (23), our results may refer to a different recruitment pattern in $\mathrm{I}_{\text {work }}$ than in $\mathrm{C}_{\text {work }}$. We do not have muscle temperature data to support the argumentation, but, 
in the study by Oksa et al (8) using the same protocol $\left(10 \%\right.$ MVC work at $\left.5^{\circ} \mathrm{C}\right)$, it was found that wrist flexor muscle temperature at a depth of $1.5 \mathrm{~cm}$ was stable around $33^{\circ} \mathrm{C}$. We thus assume that similar muscle temperature responses would have been observed during $\mathrm{C}_{\text {work }}$ and $\mathrm{I}_{\text {work }}$.

The most interesting finding of the intermittent work study was the substantially increased number of EMG gaps during $\mathrm{I}_{\text {work }}$. This finding may indicate that more variable fiber recruitment took place or that the same fibers underneath the measuring electrodes were not as active as they were during $\mathrm{C}_{\text {work }}$. This argumentation is supported by the finding of a higher level of median frequency during the concentric phase of the muscle contraction in both the flexor and extensor muscles. This finding possibly indicates that the $30 \%$ MVC work bouts induced the activity of fibers with a higher firing threshold; therefore "allowing" rest pauses for fibers with a lower firing threshold.

There was a significant difference in the EMG gaps already at the beginning of the work, whereas, for the median frequency, the difference predominantly occurred after 20 minutes of work. It could be speculated that the number of EMG gaps is a more sensitive indicator for changes in muscle function than median frequency is. In any case, the increased number of EMG gaps can be considered beneficial in terms of muscle function. According to the observation of Veiersted et al (16), cleaners who are at high risk of neck-shoulder pain had much less muscular rest (fewer EMG gaps) than office workers with lower risk (22). If we consider that the decreased number of EMG gaps indicates a risk for musculoskeletal disorders, as the results of Veiersted et al (16) indicate, our results are encouraging in terms of the well-being of workers in cold workplaces. Changing the stereotypic activation pattern by increasing the workload can increase the number of EMG gaps. Whether the use of a $30 \%$ MVC workload is the optimal alternative or whether any workload change induces the same effect remains unanswered.

Our results also indicate that the amount of fatigue was slightly less during $\mathrm{I}_{\text {work }}$ than during $\mathrm{C}_{\text {work }}$ regardless of the higher absolute workload [8939 (SE 320) versus 9476 (SE 339) in $\mathrm{C}_{\text {work }}$ and $\mathrm{I}_{\text {work }}$, respectively]. This finding was apparent for two parameters conventionally considered to be indicators of muscle fatigue $(24,25)$; a smaller decrease in the MVC and a lower average EMG at the end of work in the agonist muscles (flexors in the concentric phase of muscle contraction and the extensors in the eccentric phase) in $\mathrm{I}_{\text {work }}$. The differences between the exercise modes were not always statistically significant; however, they may still have significance from a physiological point of view. It has been postulated that fatigue is a precursor for musculoskeletal disorders (6). If this assumption is considered to be true, it seems beneficial to alter the workload intermittently to induce less fatigue in the working muscles.

The physiological mechanisms inducing a lower EMG amplitude in the flexor muscles during the concentric phase and in the extensor muscles during the eccentric phase remain difficult to explain. It may be that, due to supposedly enhanced recruitment of higher threshold fibers (needed less to produce the same amount of external work) or due to the activity of fibers outside the reach of measuring electrodes, the total amount of EMG activity remains smaller and is therefore seen as a lower EMG amplitude. As the thermal environment was the same and thermal responses were practically similar in both exercise modes, the explanation for the decreased EMG amplitude must be intrinsic in nature.

In conclusion, the cold-induced adverse effects on neuromuscular function during low-intensity repetitive work may be restored, at least partially, by intermittently increasing the workload (ie, by breaking the monotonous work cycle).

\section{References}

1. Ohlsson K, Hansson GA, Balogh I, Stromberg U, Palsson B, Nordander C, et al. Disorders of the neck and upper limb in women in the fish processing industry. Occup Environ Med. 1994;51:826-32.

2. Chen F, Li T, Huang H, Holmer I. A field study of cold effects among cold store workers in China. Arctic Med Res. 1991;50:99-103.

3. Chiang H-C, Ko Y-C, Chen S-S, Yu H-S, Wu T-N, Chang PY. Prevalence of shoulder and upper-limb disorders among workers in the fish-processing industry. Scand J Work Environ Health. 1993;19(2):126-31.

4. Yassi A, Sprout J, Tate R. Upper limb repetitive strain injuries in Manitoba. Am J Ind Med. 1996;30(4):461-72.

5. European Foundation for the Improvement of Living and Working Conditions. Second European Survey on Working Conditions. Luxembourg: Office for Official publications of the European Communities; 1996.

6. Buckle P, Devereaux J. Work-related neck and upper limb musculoskeletal disorders: report of European Agency for Safety and Health at Work. Luxembourg: Office for Official publications of the European Communities; 1999.

7. Faulkner JA, Zerba E, Brooks SV. Muscle temperature of mammals: cooling impairs most functional properties. Am J Physiol. 1990;28:259-65.

8. Oksa J, Ducharme MB, Rintamäki H. Combined effect of repetitive work and cold on muscle function and fatigue. $\mathrm{J}$ Appl Physiol. 2002;92:354-61.

9. Kadefors R, Forsman M, Zoega B, Herberts P. Recruitment of low threshold motor units in trapezius muscle in different static arm positions. Ergonomics. 1999;42:359-75.

10. Sjögaard G, Sögaard K. Muscle injury in repetitive motion disorders. Clin Orthop. 1998;351:21-31.

11. Hägg G Static work and occupational myalgia-a new expla- 
nation model. In: Andersson PA, Hobart DJ, Danoff JF, editors. Electromyographical kinesiology. Amsterdam: Elsevier Science; 1991.

12. Yona M. Effects of cold stimulation of human skin on motor unit activity. Jpn J Physiol. 1997;47:341-8.

13. Bawa P, Matthews PBC, Mekjavic IBC. Electromyographic activity during shivering of muscle acting at the human elbow. J Therm Biol. 1987;12:1-4.

14. Oksa J, Rintamäki H, Rissanen S. Muscle performance and electromyogram activity of the lower leg muscles with different levels of cold exposure. Eur J Appl Physiol. 1997;75:48490.

15. Westgaard RH, De Luca CJ. Motor unit substitution in longduration contractions of the human trapezius muscle. J Neurophysiol. 1999;82:501-4.

16. Veiersted KB, Westgaard RH, Andersen P. Electromyographic evaluation of muscular work pattern as a predictor of trapezius myalgia. Scand J Work Environ Health. 1993;19:284-90.

17. Oksa J. Neuromuscular performance limitations in cold. Int $J$ Circumpolar Health. 2002;61:154-62.

18. ISO 9920 Ergonomics of the thermal environment-estimation of the thermal insulation and evaporative resistance of a clothing ensemble. Geneva: International Standards Organisation; 1995.

19. Hardy JD, DuBois EF. The technic of measuring radiation and convection. J Nutr. 1938;15:461-75.

20. Jonsson B. Measurement and evaluation of local muscular load in the shoulder during constrained work. J Human Ergol. 1982;11:73-88.

21. Kurppa K, Viikari-Juntura E, Kuosma E, Huuskonen M, Kivi $\mathrm{P}$. Incidence of tenosynovitis or peritendinitis and epicondylitis in a meat-processing factory. Scand J Work Environ Health. 1991;17:32-7.

22. Nordander C, Hansson GA, Rylander L, Asterland P, Unge Byström J, Ohlsson K, et al. Muscular rest and gap frequency as EMG measures of physical exposure: the impact of work tasks and individual related factors. Ergonomics. 2000; 43:1904-19.

23. Merletti R, Sabbahi M, DeLuca C. Median frequency of myoelectric signal. Effects of ischaemia and cooling. Eur J Appl Physiol. 1984;52:258-65.

24. DeLuca CJ. Myoelectrical manifestations of localized muscular fatigue in humans. CRC Crit Rev Biomed Eng. 1984; 11:251-79.

25. Edwards RHT. Human muscle function and fatigue. In: Porter R, Whelan J, editors. Human muscle fatigue: physiological mechanisms. London: Pitman; 1981.

Received for publication: 26 June 2005 